\title{
Review of materials for adsorption refrigeration technology
}

\begin{abstract}
Purpose: During the last 20 years, interest in the closed adsorption heat pump and refrigeration systems has increased steadily. In this paper, consideration is given to aspects of adsorption refrigeration in terms of existing materials used in adsorption refrigeration, heat transfer characteristics of materials, and cost of materials and manufacturing. Design/methodology/approach: The paper is a general review of adsorption refrigeration technology. Findings: In recent years several papers have been published in this area and many aspects of the system have been addressed. Much effort has been devoted to enhance materials properties. Originality/value: The paper provides information of value to those involved with heat pump and refrigeration systems technology.
\end{abstract}

Keyword: Heat exchangers; Pumps; Refrigeration 